\title{
Ruth de Souza entre raça e gênero: reflexões sobre a trajetória de uma Dama negra, (1921-1954)
}

\author{
Júlio Cláudio da Silva*
}

\begin{abstract}
Resumo: Nos últimos anos o debate sobre a questão racial como variável significativa das relações sociais brasileira, ganhou expressivo espaço. Ao mesmo tempo em que a implementação da Lei 10.639/03, que estabelece o estudo da História e Cultura Afro Brasileira, demandou novos investimentos em pesquisas históricas, como estudos de cunho biográfico de personagens negros. Esse artigo toma como base a trajetória da atriz negra Ruth Pinto de Souza para refletir algumas questões relativas a presença da variável raça e gênero na sociedade brasileira.

Palavras-chave: História e Cultura Afro-Brasileira; Ruth de Souza; Relações raciais; Relações de gênero.
\end{abstract}

Abstract: In recent years the debate about the racial issue as significant variable of Brazilian social relations obtained expressive space. At the same time the implementation of the Law $10,639 / 03$ which establishes the study of African Brazilian history and culture, it had demanded new investments in historical researches, such as studies of biographical scope of black characters. This article takes as its basis the trajectory of the black actress Ruth Pinto de Souza to reflect some issues concerning to the presence of race and gender issues in the Brazilian society.

Keywords: Afro-Brazilian History and Culture; Ruth de Souza; Social relations; Gender relations.

\footnotetext{
* Professor Adjunto da Universidade do Estado do Amazonas; Doutor em História Social pelo PPGH-UFF; este artigo é fruto de nossa tese de Doutorado Relações raciais, gênero e memória: a trajetória de Ruth de Souza entre o Teatro Experimental do Negro e o Karamu House (1945-1952). Programa de Pós-Graduação em História da Universidade Federal Fluminense, Niterói. 2011, financiada pelo CNPq.
} 
No limiar do século XXI o debate em torno da questão racial como variável significativa nas relações sociais brasileiras tem conquistado cada vez mais espaço. O tema é recorrente nos meios acadêmico e social, desde o século XIX e, por ser político perpassa as produções acadêmicas, ganha as ruas e divide as opiniões entre os que reconhecem a existência da variável "raça" em nossas relações sociais e os que não a reconhecem. Não obstante a celeuma, nos últimos anos, tem havido uma tentativa de intervenção profunda na organização da Educação Básica no Brasil. Um caso emblemático é a alteração da Lei de Diretrizes e Bases (Lei. 9.394/ 1996) em função de novas atribuições previstas pela Lei 10.639/03 que estabelece a inclusão, nos conteúdos programáticos das escolas, do estudo da História da África e dos africanos, da luta dos negros no Brasil, da cultura negra brasileira e do negro na formação da sociedade nacional, resgatando a contribuição do povo negro nas áreas social, econômica e política pertinentes à História do Brasil.

A Resolução 1/2004 CNE/CP, complementar à referida lei, sugere uma lista de nomes de personagens negros a terem suas atuações estudadas, sendo três quartos deles do gênero masculino ${ }^{1}$. Entre os nomes sugeridos destacam-se Abdias Nascimento (1914-2011), escritor, ex-senador e fundador do Teatro Experimental do Negro; Edison Carneiro (19121973), antropólogo, folclorista e ativista negro; Alberto Guerreiro Ramos (1915-1982), Sociólogo e Francisco Solano Trindade (1908-1974) poeta, artista plástico, ator e ativista negro. A unidade nas trajetórias desses homens, talvez resida em suas ações intelectuais e políticas ligadas ao ativismo negro, muitas vezes seguidas de perto pela polícia política do Estado Novo e da Ditadura Civil-Militar. Contudo, convém sublinhar um dado: todos os personagens citados foram ligados aos primeiros anos de atuação do TEN e, há evidência de que ao menos dois deles, Abdias Nascimento e Solano Trindade, conviveram e acompanharam o trabalho da jovem Ruth de Souza (1921-), no TEN. A ligação desses cinco personagens ao TEN e a sua luta, torna curioso o silêncio em torno do nome da atriz face, na escrita da História da Cultura Afro-Brasileira e nos remete ao silêncio da História das mulheres e a problemática das relações de gênero na sociedade brasileira.

\section{Rompendo silêncios}

Segundo Michelle Perrot "Escrever a história das mulheres é sair do silêncio em que elas estavam confinadas”. Superá-lo pressupõe transpor a barreira estabelecida por sua

\footnotetext{
${ }^{1}$ Lei $\mathrm{n}^{\circ}$. 10.639, de 9 de janeiro de 2003. In Diretrizes Curriculares Nacionais para a Educação das Relações Étnico-Raciais e para o Ensino de História e Cultura Afro-Brasileira e Africana, Brasília, 2004, p.35. 
invisibilidade: "as mulheres são menos vistas no espaço público" atuam no ambiente doméstico, privado, em suas casas. "São invisíveis". Perrot ainda atribui parte das dificuldades de se fazer uma história das mulheres à falta de fontes e vestígios, pois sua presença é frequentemente apagada: "seus vestígios-desfeitos, seus arquivos destruídos" (PERROT, 2007: 16, 21, 22). Nossa análise contempla a história de vida de uma mulher cujo ofício de atriz de teatro, cinema e televisão a situam sob o ângulo dos holofotes garantidores de ampla visibilidade. A atuação dentro e fora do TEN fez Ruth de Souza receber "a Comenda da Ordem do Rio Branco, por seus serviços prestados à arte brasileira. Em 8 de abril de 1988" (COSTA, 2008: 118).

Desde a década de 1940, Ruth de Souza presidiu um processo de arquivamento de si, orientado pela consciência de seu pioneirismo, no processo de criação de espaço para atores e atrizes negras no cenário artístico brasileiro. A atriz reuniu um rico e variado acervo privado formado por fotografias, recortes de jornais e revistas, que cobrem o período entre as décadas de 1940 e $1960^{2}$. Ela também concedeu três depoimentos ao Museu da Imagem e do Som do Rio de Janeiro ${ }^{3}$, além das entrevistas publicadas em livros (ALMADA, 1995; COSTA, 2008; JESUS, 2004; KHOURY, 1997).

Rachel Soihet e Joana Maria Pedro ao analisarem o processo do surgimento da categoria gênero observam estar contido na categoria: "mulheres" negras, índias, mestiças, pobres, trabalhadoras, feministas. Ao mesmo tempo, a oposição das categorias mulher versus homem não é o suficiente para explicar a primeira, não obstante as "desigualdades e relações de poder entre os sexos". A principal contribuição resultante na análise de gêneros está em lançar luz sobre a invisibilidade, do ponto de vista analítico, de parte da humanidade, a mulher. Além disso, seu uso evidencia o "quanto os homens são produtos do meio social, e, portanto, sua condição é variável” (SOIHET; PEDRO, 2007: 288). Joan Scott sugere a análise dos processos de construção das relações de gênero para debater classe, raça e etnicidade ou qualquer outro processo social. Seu objetivo é clarificar e especificar "como é preciso pensar o efeito de gênero nas relações sociais e institucionais, porque essa reflexão não é geralmente feita de forma própria e sistemática". Em sua apresentação da teorização dos estudos de gênero definidos como "uma forma primeira de significar as relações de poder". Ou ainda, "gênero é um campo primeiro do seio do qual ou por meio do qual o poder é articulado" (SCOTT, 1996: 12).Meritocracia e História.

\footnotetext{
${ }^{2}$ Os documentos digitalizados constituem o Acervo Ruth de Souza/LABHOI-UFF

${ }^{3}$ Depoimento de Ruth Pinto de Souza concedido ao MISRJ nos dias: 27 de junho de 1979; e 22 de novembro de 1988 e 27 de junho de 1995.
} 
Ruth Pinto de Souza, filha de Alayde Pinto de Souza e Sebastião Joaquim de Souza morou com seus pais em um pequeno sítio no interior de Minas Gerais. Após tornar-se viúva Dona Alayde transfere-se com os filhos para uma casa de vila na Rua Pompeu Loureiro, em Copacabana. Foi neste bairro que sua mãe trabalhou como empregada doméstica e a pequena Ruth viveu parte de sua infância e juventude, frequentou escola, cinemas e descobriu sua paixão pela arte: “Aos domingos eu ia à missa de manhã e depois à tarde ao cinema. Era a programação que nós tínhamos". 4

O relato sobre esses dias revela a sua descoberta e encantamento pela arte de representar. Apesar da presença do caráter mágico, sua narrativa pontua os limites e restrições para uma menina negra tornar-se atriz na primeira metade do século XX.

A minha paixão pelo cinema vem desde a primeira vez que minha mãe levou-me ao cinema. [...]. Mas não havia bem a possibilidade de uma menina negra fazer teatro no Brasil. Não havia nada que pudesse que no momento me dissesse: vá fazer uma escola. Não existia. ${ }^{5}$

A paixão pelo cinema surgiu no final de sua infância e inicio da adolescência, já na Capital da República, provavelmente no decorrer da década de 1930. Contudo, a possibilidade de uma jovem negra tornar-se atriz, fora dos palcos dos teatros de revistas, só surgiria em 1944, com a fundação do Teatro Experimental do Negro. A narrativa desta descoberta também se dá sob o signo da magia. No entanto, são as possibilidades ou impossibilidades de uma jovem negra no Brasil da década de 1940 que pretendemos salientar.

Após ter noticia da existência do TEN, em uma matéria da Revista Rio a jovem Ruth de Souza dirigiu-se a UNE, espaço onde o grupo se abrigara acompanhada de um casal de amigos norteamericanos. Ali, fez o teste para o único personagem feminino da montagem de “O Imperador Jones”, “era um papel, uma pontinha. E eu fiz o teste e passei”. A seleção foi feita pelo próprio Abdias do Nascimento. Segundo a atriz, a produção era ainda muito incipiente, por isso tudo era "muito improvisado. Todo mundo querendo fazer alguma coisa. Mas ninguém tinha muita [...] experiência, [foi] uma aventura muito grande". 6

Todos os documentos pesquisados apontam o dia 8 de maio de 1945 como à data de estreia da jovem Ruth de Souza no TEN, a maior parte deles registra o reconhecimento de seu

\footnotetext{
${ }^{4}$ Entrevista com a atriz Ruth de Souza, concedida ao autor, em sua residência, na manhã do dia 7 de julho de 2007, no Bairro do Flamengo, Rio de Janeiro/LABHOI-UFF.

${ }^{5}$ Idem.

${ }^{6}$ Ibidem.
} 
talento desde as suas primeiras atuações. O que torna curioso o fato de sua estreia não ter ocorrido em uma companhia convencional. Por isso, nos perguntamos se o seu ingresso no teatro negro teria sido uma opção ou a falta dela? A pergunta vale para os demais integrantes de seu grupo de teatro amador. Entre os espetáculos montados pelo TEN estavam O Imperador Jones, Todos os filhos de Deus têm asas e $\mathrm{O}$ moleque sonhador, todos de Eugene O’Neill, reconhecido pelos críticos da época como "um dos maiores dramaturgos da moderna literatura americana". 7 Com o fim do ciclo de adaptações de obras estrangeiras, alguns autores passaram a escrever espetáculos especialmente para o grupo. São peças como O filho pródigo, de Lúcio Cardoso, Aruanda, de Joaquim Ribeiro, e Filho de Santo. Todos estes espetáculos foram montados pelo TEN entre os anos de 1945 e 1949. Parte dos objetivos do surgimento do TEN tornou possível a montagem de espetáculos que iluminaria temáticas socioculturais da população negra. Bem como possibilitar aos atores e atrizes negros interpretar dramas, comédias e textos de repertório clássico, como Otelo, de Shakespeare.

Nos recortes de periódicos do Acervo Ruth de Souza são fartos os registros de seu celebrado desempenho como atriz. Ainda durante o período de sua atuação no TEN. Para Aldo Calvet, Aruanda foi um espetáculo “interessante". Nessa montagem o único desempenho elogiado foi o da atriz Ruth de Souza. O trecho sublinhado com caneta azul, provavelmente pela própria atriz, traz o seguinte comentário: "A Sra. Ruth de Souza aparece num desempenho brilhante, dando relevo à figura tão marcante de 'Tia Zefa". ${ }^{8}$ Paschoal Carlos Magno criticou o texto de Aruanda e ressaltou o valor da cenografia de Santa Rosa, a música de Gentil Puget e as interpretações de Ruth de Souza, Abdias Nascimento e Claudiano Filho. ${ }^{9}$ Os elogios à intérprete de Tia Zefa indicam qual avaliação o crítico possuía a respeito da jovem atriz. "Ruth de Souza não encontrou ainda ocasião para mostrar a força de um imenso talento. Que dramaturgo novo ou velho escreverá especialmente uma peça pensando nessa grande intérprete negra?". 10

Em relação ao desempenho do elenco do TEN os críticos enfatizaram o nível do desempenho da atriz em "Os filhos de santo".

O crítico teatral mais hermético vê-se na contingência de abrir coluna para elogiar a atuação da senhora Ruth de Souza, cujo jogo de cena,

\footnotetext{
${ }^{7}$ NONATO, Áureo. O teatro do negro no Brasil. Universal, agosto-setembro de 1948, p.36. Acervo Ruth de Souza/LABHOI-UFF.

${ }^{8} \mathrm{O}$ nome do periódico e a data estão escritos a caneta. CALVET, Aldo. Folha Carioca. Sem local, 27 de dezembro de 1948. Acervo Ruth de Souza/LABHOI-UFF.

9 Sem indicação de autoria. Correio da Manhã. Sem local, 28 de dezembro de 1948. Acervo Ruth de Souza/LABHOI-UFF.

${ }^{10}$ Idem.
} 
cuja ginástica de máscara a tornam habilitada para figurar ao lado de quantas atrizes dramáticas tenham entre nós integrado o elenco de Companhias regulares. Magra como é, macilenta, quase exótica, portadora de um timbre impressionante de voz, ei-la capaz de encenar qualquer papel em que a sua personalidade tenha ambiente para firmar-se por si mesma. ${ }^{11}$

Segundo a avaliação do crítico, o mais hermético de seus pares não poderia deixar de tecer, em sua coluna, elogios ao desempenho da jovem Ruth de Souza. Ele era capaz de colocá-la ao lado de qualquer atriz dramática das companhias tradicionais. A jovem atriz já reunia condições de interpretar qualquer personagem, compatível com suas características físicas e cênicas. Vale ressaltar que tais considerações foram registradas em 1949, no período anterior aos seus estudos para aprimoramento do oficio de atriz nos Estados Unidos. E, cinco anos antes de, na condição de atriz profissional, tornar-se, provavelmente, a primeira atriz brasileira a concorrer ao prêmio de melhor atriz no Festival de Veneza. As críticas e premiações recebidas pela atriz, já no inicio de sua trajetória, no período em que atuava principalmente no teatro e no cinema, apontam para o surgimento de um grande nome a ser consagrado dentro dos cânones das artes cênicas brasileira, não obstante a sua origem étnicoracial.

Dentre as centenas de recortes de periódicos do Acervo Ruth de Souza, aos poucos, vão surgindo pequenas notas e matérias com novos conteúdos relativos ao início de sua profissionalização: as suas atividades no teatro e no cinema, portanto fora do TEN. Segundo Schumaher e Vital Brasil, a primeira atuação profissional da jovem Ruth de Souza teria ocorrido em Os Comediantes (SCHUMAHER; VITAL BRASIL. 2000: 493). Quando Ruth de Souza integrou o elenco do espetáculo Terras do Sem Fim, em 1948, uma adaptação do livro homônimo, de Jorge Amado, para o teatro. A peça foi montada por Os Comediantes, sob a direção de Zigmunt Turkov, a trilha sonora ficou a cargo de Dorival Caymmi. No elenco, estavam Cacilda Becker, Jardel Filho, Maria Della Costa e Ziembinski. No mesmo ano, a atriz também teria participado da versão para o cinema do mesmo livro, chamada Terra violenta, e atuado no filme Falta alguém no manicômio, de Carlos Burle, com participação de Oscarito e produzido pela Atlântida. Ainda em 1948, atuou, no Teatro Ginástico, na peça A família e a festa na roça, de Martins Pena, ao lado de Abdias Nascimento, Bibi Ferreira, Procópio Ferreira, Sérgio Cardoso e Jardel Filho; e em Mensagem sem rumo, peça de Agostinho Olavo; além de sua já mencionada atuação em Aruanda.

${ }^{11}$ COSTA, J. Rego. Teatro: Filhos de santo. Vanguarda. Sem local, sem data. Acervo Ruth de Souza/LABHOIUFF. 
Em 1949, atuou no filme Também somos irmãos, de José Carlos Burle. No teatro, participou das peças Filho de santo, Calígula, de Eros Martins, produzido pelo TEN e Balão caiu no mar, de Odilo Costa Filho. No ano seguinte, Ruth de Souza teria participado do filme A sombra da outra. Segundo Haroldo Costa, neste ano a atriz teria recebido a bolsa para estudar nos EUA. Contudo, os cotejos da documentação da época revelam outros dados. Entre 1951 e 1952 Ruth de Souza fez cursos de aprimoramento técnico em escolas norteamericanas, graças à referida bolsa de estudos. Neste período atuou no teatro-escola Karamu House, nos espetáculos Dark of the Moon, Street scene, Shadow of a gunman.

Ainda sobre o período de atuação profissional da atriz, a documentação do Acervo Ruth de Souza, também apresenta críticas e comentários sobre a sua participação em outros filmes como Ângela, produzido pela Vera Cruz; a cobertura do I Festival Internacional de Cinema, realizado em São Paulo, como parte dos festejos do quarto centenário da fundação da cidade; sua atuação em Candinho, de 1954, ao lado de Mazzaropi e Maria Prado, escrito e dirigido por Abílio Pereira de Almeida, também na Vera Cruz.

Nove anos após estrear no Theatro Municipal, Ruth de Souza era festejada e anunciada como "a maior atriz de cor do cinema nacional e, também um dos seus mais expressivos vultos artísticos”. Em outras palavras, a maior atriz afrodescendente situava-se entre as principais atrizes brasileiras. Ao seu lado, com os mesmos adjetivos destinados a situá-lo no universo artístico masculino, encontrava-se Grande Otelo. Exatamente pela equivalência das posições no cenário artístico nacional, as fotografias dos dois atores estão lado a lado sobre notas definidoras. E, assim iniciam a matéria "Cinema Brasileiro: os intérpretes de cor em nosso cinema", publicada em A Cena.

O cerne do texto chama atenção por sua atualidade face às demandas de movimentos sociais e determinações oficiais do Estado brasileiro estabelecidas pela já referida lei 10.639/2003. Em especial, no que tange à valorização da história e cultura africana e afrodescendente na formação social, econômica e cultural do Brasil. Ao que parece, por mais de meio século, a visibilidade do encaminhamento de uma solução dessa demanda parece ter ficado congelado.

O negro compõe a paisagem humana brasileira. É uma das 'três raças tristes'. Sua contribuição para o desenvolvimento econômico e cultural de nossa terra é fato incontestável. Hoje, como outrora, presta sua colaboração ao desenvolvimento do país erguendo e solidificando a indústria. Nossa música muito the deve. Nossos ouvidos ainda ressoam as cantigas de ninar entoadas pela 'Mãe preta' e as lendas contadas pelo 'Pai João'. O negro não conseguiu, via de regra, galgar os degraus mais elevados da sociedade. Agrava a sua condição de 
analfabeto e o preconceito racial que sobreveio nos espíritos reacionários que criam uma barreira aos homens de cor. O cinema, como manifestação artística de grande alcance, não pode deixar de encarar o problema e de dar oportunidade aos intelectuais negros do Brasil se manifestarem. ${ }^{12}$

Caberia ao cinema contemplar a dimensão política da temática, no caso a contribuição dos africanos e afrodescendentes na área social, econômica e política para a constituição histórica do Brasil, as desigualdades e a discriminação racial. Para o autor, os negros apareciam, em muitos filmes, em circunstâncias que não caracterizam uma "apresentação negativa". Apesar disso, o articulista critica a valorização do "aspecto de superfície - o exclusivamente plástico". As cenas de percussão dos rituais religiosos afrodescendentes, de "hercúleos pescadores" ou ainda da "mulatinha de linhas insinuantes etc.”. Outro aspecto rejeitado é o mote da chacota. Uma situação recorrente no cinema brasileiro, muitas vezes protagonizada pelo próprio ator afrodescendente, caracterizando um "desrespeito por si próprio e pelos outros e não pode este fato ser encarado com remissão". ${ }^{13}$

Assim, alguns filmes representam iniciativas válidas e louváveis: "Porém, não atingiram o problema com objetividade, descambando para o melodrama inconseqüente". Nessa classificação, estavam os filmes Moleque Tião, Também somos irmãos, Sinhá Moça, $\mathrm{Saci}^{14}$, todos considerados superficiais ao abordar o tema negro. Até o presente momento, sabemos que, ao menos dois desses filmes contaram com a participação da jovem Ruth de Souza. Ainda está a ser feito um estudo sobre os significados, para a época, destes filmes e da participação da atriz.

Outro aspecto criticado na matéria é a participação numérica dos atores negros, apesar de não serem poucos, na década de 1950. Segundo o autor, raramente o cinema brasileiro os assimilavam. Nesse tocante, Ruth de Souza e Grande Otelo era exceção. Outros nomes também apareciam com menor frequência, a "Negra Felicidade", em o Caiçara, Paulo Matozinho, intérprete do papel principal em $O$ Saci, Joça, Pérola Negra, Claudiano Filho, Benedita, Marina Gonçalves, entre outros. "Muitas são as lutas travadas nos bastidores para se conseguir um papel de maior responsabilidade. Luta onde vale quase tudo!”. ${ }^{15}$

O artigo traz as impressões de três intelectuais negros sobre o cinema, em 1954, Abdias Nascimento, Solano Trindade e Ironildes Rodrigues. Para efeito de análise,

\footnotetext{
${ }^{12}$ SANIN."Cinema Brasileiro: os intérpretes de cor em nosso cinema. A cena. Sem local. Acervo Ruth de Souza/LABHOI-UFF.

${ }^{13}$ Idem.

${ }^{14}$ Idem.

${ }^{15}$ Idem.
} 
consideramos somente as do primeiro, por nos fornecerem indícios sobre o seu pensamento a respeito do cinema e, consequentemente, dos processos possíveis de profissionalização de seus companheiros do TEN. Para Abdias Nascimento, "o cinema brasileiro não aborda com coragem o problema do homem de cor". Em sua autoavaliação, define-se como possuidor de recursos cênicos para tal, mas nunca teria participado de um filme. Por outro lado, o TEN teria sido uma significativa fonte de atores negros para o cinema, o teatro nacional e inúmeros figurantes para "os filmes que precisam multidões negras". ${ }^{16}$ Além de Ruth de Souza, Marina Gonçalves, Claudiano Filho, Aguinaldo Camargo e, porque não, Lea Garcia, poucos atores do TEN profissionalizaram-se. O próprio grupo, no decorrer do tempo, não se deslocou nessa direção. As afirmações de Abdias Nascimento nos fornecem pistas sobre essa opção. Com uma expressiva dimensão política, o TEN criticou o racismo nos palcos e na sociedade brasileira, as montagens teatrais orientadas pelo interesse comercial e defendeu o processo de modernização do teatro. Parte das críticas destinadas ao teatro também poderia ser direcionada ao cinema.

\begin{abstract}
As circunstâncias históricas não têm favorecido o homem de cor, é o que nos diz Abdias. $\mathrm{O}$ cinema tem se mantido fiel a estas absurdas tradições. O cinema se quiser abordar um problema desta natureza terá de se socorrer de argumentistas negros, os únicos capazes de sentir a autenticidade da questão. Dos filmes que abordaram o problema do homem de cor 'o melhorzinho' foi Também somos irmãos. Mesmo em Sinhá Moça o problema foi mutilado em todos os sentidos. Argumentos fabulosos, que se prestariam à magnífica exploração cinematográfica, têm sido desprezados para atender ao cosmopolitismo - doença da moda e que tanto nos prejudica. ${ }^{17}$
\end{abstract}

Para o antigo companheiro do TEN, o cinema não refletia ou discutia adequadamente as diferenças e desigualdades sociais vividas pelos negros ao longo da história. Outra perspectiva desse problema viveu a atriz profissional, atuante em companhias comerciais. Sua principal questão era a própria sobrevivência como profissional. E os limites enfrentados por uma atriz negra na luta por um lugar no firmamento das grandes estrelas, não obstante o expressivo reconhecimento de seu desempenho profissional obtido no exterior.

A participação em Sinhá Moça e, por conseguinte, a repercussão nacional e internacional do filme e do seu desempenho, foi um marco na carreira de Ruth de Souza. O filme, do gênero drama, foi produzido pela Companhia Vera Cruz, em 1953. A direção coube a Tom Payne, e contou com a atuação de Anselmo Duarte, Eliane Lage, Ruth de Souza e

\footnotetext{
${ }^{16}$ Idem.

${ }^{17}$ Idem.
} 
grande elenco. A trama baseia-se no romance homônimo, da escritora Maria Dezonne Pacheco Fernandes ${ }^{18}$ e transcorre em um contexto de fuga escrava e da abolição da escravidão. As críticas e a cobertura da participação de Sinhá Moça no Festival de Veneza e no I Festival Internacional de Cinema de São Paulo constituem uma parte significativa do acervo do Acervo Ruth de Souza/LABHOI-UFF.

Um dos recortes selecionados indica ter sido "o primeiro prêmio internacional para a melhor interpretação feminina, ou mais precisamente, o 'Leão de Ouro' de Veneza", concedido à Lilli Palmer, graças a sua atuação no filme The four poster, originalmente uma peça de sucesso levada para as telas de cinema. Sobre a nota, uma fotografia da atriz norteamericana em uma cena da atuação premiada. ${ }^{19}$

O subtítulo, "Ruth de Souza adquire projeção internacional", divide a matéria ao meio. Segundo o articulista, "até o último dia da bienal, a famosa atriz brasileira esteve cotada para receber o prêmio de interpretação. Na recente bienal o filme Sinhá Moça foi apresentado e contemplado com o prêmio Leão de Bronze. Segundo Franco Zampari, presidente da Vera Cruz, até o último dia, entre os jurados, uma das atrizes do filme estava na disputa pelo prêmio de melhor atriz, ou em suas palavras, 'esteve ainda cotada para levantar a láurea de interpretação uma de suas principais figuras, a atriz Rute de Souza"”. ${ }^{20}$ O Festival Internacional de Veneza - Mostra Internazionale d'Arte Cinematografica - acontece desde 1932. Embora seja anual, faz parte da Bienal de Veneza, exposição internacional de arte ocorrida naquela cidade.

Contudo, a atriz brasileira não foi contemplada com um prêmio no festival italiano, o contrário aconteceu no de São Paulo. O jornal Última Hora reproduziu a noticia da premiação feita pelo O Estado de São Paulo, no artigo "Os 'saci' de cinema de 1953". No dia anterior, no I Festival Internacional de Cinema, realizado como parte dos festejos do quarto centenário da fundação da cidade. O evento premiou o melhor filme, ator, atriz, diretor, atriz coadjuvante, entre outras categorias. Ruth de Souza foi contemplada com o prêmio de melhor atriz coadjuvante, por sua participação em Sinhá Moça. ${ }^{21}$

O reconhecimento da qualidade de seu desempenho profissional tornou possível tomar seu nome como uma das referências, em uma matéria onde se discutiu igualdade de

\footnotetext{
${ }^{18}$ Sem Autor. "Flan recomenda". Sem Indicação de Local, Sem indicação de Data. Acervo Ruth de Souza/LABHOI-UFF.

${ }^{19}$ Sem Autor. Lilli Palmer triunfa em Veneza. Folha da Noite. S/L, 21 de setembro de 1953. Acervo Ruth de Souza/LABHOI-UFF.

${ }^{20}$ Idem.

${ }^{21}$ S/A. Os 'saci' de cinema de 1953. Última Hora, 6 de setembro de 1954. Acervo Ruth de Souza/LABHOIUFF.
} 
gênero. Seu conteúdo, claramente panfletário, chama a atenção pela efetiva consciência sobre o tema, expressa na proposta de reflexão pública. O pressuposto da igualdade parece ter sido compartilhado pelos leitores, entre os quais Ruth de Souza. "Elas não perdem para os homens" foi publicado na Revista da Semana, provavelmente nos primeiros anos da década de 1950. O objetivo da matéria é colocar, lado a lado, 32 nomes de homens e mulheres para demonstrar como o gênero feminino "pode perfeitamente ombrear os congêneres masculinos. Ombrear com eles e, muitas vezes enfrentá-los e superá-los”. Entre as dezenas de nomes selecionados, representando as diversas categorias profissionais, estavam os de Raquel de Queiroz, como escritora; Cecília Meireles, poetisa; Wanda de Castro e Isa de Almeida, nadadoras; Ângela Maria e Araci de Almeida, cantoras do rádio, Ivete Vargas e Conceição Santamaría, na política; e Dulcina de Moraes e Ruth de Souza, no teatro ${ }^{22}$. À luz do conteúdo desta matéria, vale a pena relembrar as definições de Joan Scott em relação à análise dos processos de construção das relações de gênero para debater classe, raça e etnicidade ou outro processo social qualquer. Assim, gênero "é uma forma primeira de significar as relações de poder". Ou ainda, "gênero é um campo primeiro no seio do qual ou por meio do qual o poder é articulado".

Nos anos cinquenta, houve matérias enfatizando o potencial de igualdade de homens e mulheres. Outras iluminaram os limites que enfrentou "O artista negro". O subtítulo da matéria publicada na Revista do Globo é bastante significativo em relação ao lugar possível de ser alcançado pelo "artista negro" no firmamento das grandes estrelas do teatro e cinema brasileiro. "Ruth de Souza, uma das mais inteligentes artistas do nosso cinema deseja melhores papéis para si mesma e seus irmãos de raça, mas reconhece a dificuldade de vencer um tabu imposto por Hollywood". Apesar de seus méritos, trata-se de uma mulher, negra, de origem humilde, na sociedade brasileira das décadas de 1940 e 1950. Naquela época, Ruth de Souza morava na Rua da Abolição, em São Paulo. Antes da entrevista, parece ter havido, em sua casa, uma reunião de artistas e intelectuais. Entre os presentes estava Marisa Prado, Fernando de Barros, José Mauro de Vasconcellos, "o romancista de Banana Brava e de A Arara Vermelha", Margalô Bruce, cantora. Apesar de pequeno grupo, a descrição nos remete a outras, a dos espaços de sociabilidade frequentados pela atriz no Rio de Janeiro. ${ }^{23}$

Segundo Fernando Góes, o diálogo com a entrevistada foi iniciado com um pingpong, onde a bola atinge vários ângulos, até fixar-se na temática racial: “o problema do artista

\footnotetext{
${ }^{22}$ S/A. "Elas não perdem para os homens". Revista da Semana. S/L, S/D. Acervo Ruth de Souza/LABHOI-UFF.

${ }^{23}$ GÓES, Fernando. O artista negro. Revista do Globo. Sem local, 26 de julho de 1954. Acervo Ruth de Souza/LABHOI-UFF.
} 
de cor, ou mais precisamente, da atriz negra". Na seção de sugestivo título, "Deus tem sido fabuloso", Góes explica ter a temática racial surgido espontaneamente na entrevista ou, em suas palavras, "o tema veio por acaso". Foi o desdobramento de uma pergunta, segundo o autor, feita sem a menor pretensão: "se ela estava satisfeita com os papéis secundários que até agora lhe foram reservados, de escrava humilde de criada, e se não tem ambições de ir além dessas 'pontas', de ser mais do que uma coadjuvante". ${ }^{24}$ A pergunta é direta, objetiva, tangencia na questão racial, uma vez que foi formulada após os debates sobre o tema promovido pelo TEN na década anterior e foi formulada a um de seus expoentes. Poderíamos refazê-la. Para além das criticas sobre o espaço para atores e personagens afrodescendentes, quais foram os limites enfrentados por uma atriz desse segmento, não obstante seu aprimoramento técnico-profissional e a forte candidatura a uma premiação no Festival de Veneza?

A entrevistada explica não ser este um acontecimento dependente de sua vontade. Pelo contrário, desejava "fazer algo mais completo, mais definitivo, um trabalho em que possa me revelar por inteiro, dar a minha exata medida”. Àquela altura não mais falava a partir de um grupo experimental, mas do círculo de artistas e intelectuais profissionais, com regras de mercado, implícitas e explícitas, muito bem definidas. Talvez seja esse o motivo para a atriz prosseguir sua resposta despersonalizando os atores sociais envolvidos e esvaziando o conteúdo racial do tema. "O problema é que os escritores de cinema são preguiçosos, vamos dizer assim, e se esquecem que os negros podem servir à arte de uma forma mais completa, mais integral”. Na década de 1950, a atriz faz uma descrição de si e de sua carreira que remete ao transcendente. Uma estratégia discursiva presente em vários outros depoimentos e entrevistas concedidas no decorrer de sua vida. Talvez assim fosse possível, fugir à discussão política sobre raça e mérito, dedicando suas energias para as batalhas diárias de sobreviver em um mercado/sociedade marcado por essas desigualdades.

No meu caso, não me canso de dizer que Deus tem sido fabuloso comigo, que tem me acontecido verdadeiros milagres. Porque não se pode compreender por outra forma a acolhida que o meu trabalho tem tido do público e da crítica, quando os meus papéis tem sido, de um modo geral, absolutamente sem importância. ${ }^{25}$

Assim como o teatro comercial estabeleceu um padrão estético e temático combatido pelo TEN a partir de 1944, no argumento da atriz o cinema teria sido dominado por uma

\footnotetext{
${ }^{24}$ Idem.
}

${ }^{25}$ Idem. 
espécie de paradigma similar, estabelecido por Hollywood. Por isso seu aproveitamento como atriz principal não dependeria somente do script. "O lado econômico é importantíssimo, pois de certo modo o tabu de Hollywood é ainda o que domina. Isto é, vivemos, ainda, sob o império da mocinha bonita, das histórias de mocinho e mocinha". ${ }^{26}$ O modo como eram encaminhadas as temáticas ligadas à história e à condição social do afrodescendente foi objeto de críticas por parte de Abdias Nascimento. Segundo o relato de Ruth de Souza, nessa entrevista, em 1954, os temas que davam grande visibilidade a esses atores não possuíam perfil comercial.

Para se ter uma atriz afrodescendente como "figura principal de um filme", era necessário "coragem" aos nossos produtores e companhias. Naqueles dias, Ruth de Souza teria conversado com Lima Barreto sobre um filme denominado Mau olhado. "Um argumento que ele trataria esplendidamente, porque tem coragem suficiente para isso". Mas a entrevistada atuava em importantes companhias do circuito profissional do cinema. $\mathrm{O}$ grupo de arte experimental ficara no passado. Por isso, ato contínuo, a própria atriz reconheceu ser Mau olhado um argumento para filmes de festivais e não comerciais. Diante desse impasse, perguntou-se: "E como conseguir, se de antemão reconhecemos isso, o financiamento necessário?"27

Fernando Góes parece não ter ficado satisfeito e queria saber como a produção literária nacional poderia ser aproveitada de modo a fornecer um papel principal a uma atriz afrodescendente.

Ruth de Souza conta que dos Males, de Pedro Calmon, poderia ser extraído um argumento magnífico. É a história rica de ação, de movimento, de situações palpitantes, de uma das mais famosas insurreições de negros na Bahia, no século passado. E nela, uma negra, Luíza Mahin, a mãe de Luís Gama tem papel destacado. - Esse é o papel que eu faria com paixão. ${ }^{28}$

Não podemos deixar de fazer uma observação, dos vários ângulos atingidos pela bola-tema, na entrevista ping-pong, para a elaboração da matéria jornalística, somente a temática racial foi recuperada. Apesar da sutileza e descrição do entrevistador e da entrevistada, Fernando Góes parece estar interessado em discutir essa questão. Por outro lado, a matéria foi selecionada para constar no Arquivo Ruth de Souza, fixada em uma de suas

\footnotetext{
${ }^{26}$ Idem.

${ }^{27}$ Idem.

${ }^{28}$ Idem.
} 
páginas. Em certa medida, tem a função de registrar aspectos das reflexões acerca das relações raciais e de gênero vividas pela atriz. Nesse sentido, os escritos equivalem a uma página de diário, guardada em meio a dezenas e dezenas de comentários acerca de seu bom desempenho em papéis coadjuvantes. Em outras palavras, no processo de arquivamento de si e do TEN, com claro objetivo biográfico, o documento armazena aspectos das relações raciais e de gênero, para a posteridade. Elementos de uma trajetória pouco visitada, pela atriz. Certamente por não se constituir em uma variável ou experiência capaz de contribuir na luta por um lugar no firmamento das grandes estrelas, do país da suposta democracia racial. Sua principal meta ao profissionalizar-se como atriz.

\section{Considerações finais}

Ruth Pinto de Souza teve o reconhecimento de seus méritos como atriz, de teatro, cinema e televisão nas críticas e prêmios recebidos em sua longa carreira profissional. Do prêmio Saci, o seu preferido, por sua atuação em Sinhá Moça (1953) ao Kikito de melhor atriz no XXXII Festival de Gramado (2004), passando por várias outras críticas, positivas sobre o seu desempenho, ao longo de sua vida profissional. Protagonista ou coadjuvante, memória e esquecimento, visibilidade e invisibilidade são binômios reveladores de aspectos importantes na história das relações de gênero e raça na sociedade brasileira. Mormente ao fazermos a partir da trajetória de Ruth de Souza. E é nesse sentido que $O$ artista negro, de Fernando Góes é um documento emblemático revelador dos limites enfrentados por uma atriz afrodescendente no Brasil. Mais que isso, é indicador do lugar possível, não obstante aos pioneirismos e méritos, no firmamento das grandes estrelas de teatro, cinema e televisão brasileira.

Restrições também identificadas pelos interlocutores da atriz durante o primeiro depoimento concedido por Ruth de Souza ao Museu da Imagem e do Som do Rio de Janeiro, vinte e cinco anos depois da entrevista concedida a Fernando Góes.

Quando o tema voltou à baila. Após discorrer sobre a história de sua atuação em Sinhá Moça, uma das suas entrevistadoras observou: “Ainda não entendi por que não deram um papel bom para essa mulher? Por que ela está muito acima do cinema brasileiro". ${ }^{29}$ A entrevistada não chegou a responder a pergunta, pois uma segunda lhe foi acrescentada. Um segundo interlocutor fez-lhe outra questão, com objetivo de obter maior esclarecimento e

\footnotetext{
${ }^{29}$ Depoimento da atriz Ruth de Souza para a série Som Ciclos de Cinema, Teatro e Televisão do Museu da Imagem e do Som. Rio de Janeiro, 27 de junho de 1979.
} 
registro sonoro para a posteridade de tema tão delicado, referente às estruturas de relação de poder em nossa sociedade.

- Daí por diante você tem feito muito coisa. Mas aquele papel que você deseja fazer, quase sempre lhe foi negado. Conta essa história. É preconceito, é estupidez, ou realmente é falta de oportunidade, para eu ser bem delicado.

- Olha são as três coisas juntas. [Respondeu uma entrevistadora, no lugar da atriz]..$^{30}$

Ruth de Souza não possui em sua biografia as características clássicas dos indivíduos que, em geral, são alçados à condição de personagem histórico. Não atuou na arena política, nos partidos políticos, sindicatos e diversas formas associativas. Tampouco foi uma intelectual ou ativista produtora de textos reflexivos, críticos ou panfletários da causa da população africana ou dos afrodescendentes em diáspora. Mas travou uma batalha cotidiana para a criação e ampliação de espaço de atuação profissional de homens e mulheres afrodescendentes nos palcos de teatro, no cinema e na televisão brasileira. Rompeu barreiras ao tornar-se atriz, em uma época em que a profissão não era bem vista para uma mulher de boa família. E que os poucos personagens negros eram encenados por atores brancos, com os rostos pintados de preto. Em meio ao binômio memória e esquecimento a lembrança de seu nome remete ao lugar na história de uma parte significativa da população brasileira, as mulheres. Sua história de vida é um caso emblemático da presença das variáveis raça e gênero nas relações sociais no Brasil do século XX.

\section{Referências Bibliográficas}

ALMADA, Sandra. Damas Negras: sucesso, lutas e discriminação: Xica Xavier, Lea Garcia, Ruth de Souza, Zezé Motta. Rio de Janeiro: Mauad, 1995.

COSTA, Haroldo. Álbum de Retratos: Ruth de Souza. Rio de Janeiro: Memória Visual; Folha Seca, 2008.

Diretrizes Curriculares Nacionais para a Educação das Relações Étnico-Raciais e para o Ensino de História e Cultura Afro-Brasileira e Africana. Brasília: 2004.

JESUS, Maria Ângela. Ruth de Souza: a estrela negra. São Paulo: Imprensa Oficial do Estado de São Paulo, 2004.

KHOURY, Simon. Bastidores V: entrevistas. Rio de Janeiro: Jotanesi, 1997.

PERROT, Michelle. Escrever a história das mulheres. In: Minha história das mulheres. São Paulo: Contexto, 2007.

SCOTT, Joan. Gênero: uma categoria útil para a análise histórica. In: SOS corpo. Recife, abril de 1996.

${ }^{30}$ Idem. 